TAPROBANICA, ISSN 1800-427X. June, 2014. Vol. 06, No. 01: pp. 1-6, 1 pl.

(C) Research Center for Climate Change, University of Indonesia, Depok, Indonesia \& Taprobanica Private Limited, Homagama, Sri Lanka

http://www.sljol.info/index.php/tapro

\title{
POPULATION DENSITY AND BIOMASS OF THE WILD PREY SPECIES IN A TROPICAL DECIDUOUS FOREST, CENTRAL INDIA
}

\author{
Kannadasan Narasimmarajan ${ }^{1,2}$, Subhasis Mahato ${ }^{1}$ and Abinash Parida ${ }^{1}$
}

\footnotetext{
${ }^{1}$ Wildlife Institute of India, Post Box no. 18, Chandrabani, Dehradun, India

${ }^{2}$ Department of Zoology, Madras Christian College, Tambaram, Chennai 600059, Tamil Nadu, India

E-mail: wildlife9protect@gmail.com
}

\begin{abstract}
For proper management of a wildlife reserve, it is essential to estimate density and biomass of herbivores that in turn determine the density of carnivores. We estimated the population density and biomass of three ungulates and two other species in the Melghat Tiger Reserve, Central India. The study was conducted from September 2010 to April 2011. We used distance sampling to estimate the population density of wild prey species. The $225 \mathrm{~km}^{2}$ intensive study area was found to have high prey species density $\left(69.5 \pm 8.3\right.$ individuals $\left./ \mathrm{km}^{2}\right)$, with gray langur being the abundant prey species $\left(42.9 \pm 7.2\right.$ individuals $\left./ \mathrm{km}^{2}\right)$, followed by sambar $\left(10.5 \pm 3.5\right.$ individuals $\left./ \mathrm{km}^{2}\right)$, gaur $(5.8 \pm 1.7$ individuals $\left./ \mathrm{km}^{2}\right)$, barking deer $\left(2.7 \pm 0.3\right.$ individuals $\left./ \mathrm{km}^{2}\right)$, and peafowl $\left(7.6 \pm 0.6\right.$ individuals $\left./ \mathrm{km}^{2}\right)$. When the density figures were multiplied by the average weight of each prey species, biomass of $6501.8 \mathrm{~kg} / \mathrm{km}^{2}$ was obtained.
\end{abstract}

Key Words: Abundance; Anthropogenic; Carnivore; Gugamal National Park; Melghat Tiger Reserve.

\section{Introduction}

The population density and biomass of large herbivore species have often been used to compare the carrying capacity of different habitats. As the herbivore biomass forms the bulk of the prey base, it also determines the population density of large carnivores (Dinerstein, 1980; Kumara et al., 2012). Recent biological modeling demonstrated that the prey depletion can lead to drastic decline in the tiger population size; thus the population sizes of prey and predator are interdependent (Karanth et al., 2004). Maintenance of the healthy population of herbivore species is indeed required for the survival and maintenance of viable population of large carnivore species. This necessitates the need for data on the density and biomass of potential prey species of large carnivore habitats in the protected areas. Population estimation, either by direct or indirect surveys, is crucial to determine abundance, density and distribution of wild animals (Dinerstein, 1980). In case of semi- 
gregarious animals such as gaur (Bos frontalis) and sambar (Rusa unicolor) etc., use of line transect based direct sightings have been commonly applied to estimate their density (Kumara et al., 2012). Information regarding population density, biomass and grouping tendency of the wild prey species in tropical deciduous forests is scanty (Karanth et al., 2004) particularly in Melghat Tiger Reserve (MTR), where only limited information is available in the recent past (Buckland et al., 2001). So, in order to fill the information gap we conducted a systematic survey to estimate wild prey density through distance sampling method. Distance sampling by line transect method is more robust as it allows a more accurate estimate of population size than other methods, and it addresses detectability issues (Buckland et al., 2001; Jathanna et al., 2003). Moreover, the method has been proved to work well in tropical forests of the Indian subcontinent (Harihar et al., 2009; Karanth \& Nichols, 2002; Narasimmarajan et al., 2012). Distance sampling offers a reliable estimation of animal densities comparable to results of the mark-recapture method, and has also proven to be cost-effective and less invasive (Kumara et al., 2012).

\section{Materials and Methods}

Study Area: MTR almost entirely falls in the Satpura and Mikal landscape characterized by rugged hills ranging from $600-1,100 \mathrm{~m}$ a.s.l with a low water table and streams disappearing into permeable sediments during summer. The total area of the tiger reserve is about $1,676 \mathrm{~km}^{2}$, including $361 \mathrm{~km}^{2}$ notified as Gugamal National Park $\left(20^{\circ} 51^{\prime}-21^{\circ} 46^{\prime} \mathrm{N}\right.$, $\left.76^{\circ} 38^{\prime}-77^{\circ} 33^{\prime} \mathrm{E}\right)$ which falls under two districts, Akola and Amravati in Maharashtra (Narasimmarajan et al., 2012). Within the Gugamal NP, Dhargad, Dhakna and Chikaldara forest ranges (FR) covering $225 \mathrm{~km}^{2}$ were selected as the study area. The Melghat region experiences tropical climate with temperatures ranging from $13^{\circ} \mathrm{C}$ in winter and $45^{\circ} \mathrm{C}$ during summer. The annual rainfall ranges from $1000-$ $1800 \mathrm{~mm}$. The overall land cover matrix consists of natural forests interspersed with agricultural and forestry crops. The natural vegetation consists of both moist as well as dry deciduous forests, with the north facing hills dominated by Tectona grandis (Lamiaceae) and the south facing slopes covered by mixed forests comprising of tree species such as
Terminalia alata (Combretaceae), Anogeissus latifolia (Combretaceae), Lagerstroemia parviflora (Lythraceae), Terminalia bellerica (Combretaceae), Madhuca indica (Sapotaceae), and Dendrocalamus strictus (Poaceae) (Narasimmarajan et al., 2012). Extensive shrubs of Colebrookea oppositifolia (Lamiaceae), Azanza lamaps (Malvaceae), and Carvia callosa (Acanthaceae) occur in relatively undisturbed valleys and the grasslands comprising of Cynodon dactylon (Poaceae), Themeda triandra (Poaceae) and Eragrostis curvula (Poaceae) occur intensely in un-grazed areas. Tiger (Panthera tigiris), leopard (Panthera pardus) and dhole (Cuon alpinus) are the principal large carnivores. The Indian gaur (Bos frontalis); sambar (Rusa unicolor); nilgai (Boselaphus tragocamelus); wild pig (Sus scrofa); red muntjak (Muntiacus muntjak); southern gray langur (Semnopithecus dussumieri); Indian hare (Lepus nigricollis); and peafowl (Pavo cristatus) are the more commonly encountered wild prey in the study area. Domestic livestock (Bubalus bubalis, Bos Taurus) ranging from the villages on to the forest boundaries also forms potential prey base for the large carnivores. The chital (Axis axis) is found only in few localities of the park (Mahabal, 2005).

Assessing Population Density: To assess the population abundance of wild prey species, we used line transects with conventional distance sampling (Anderson et al., 1979; Buckland et al., 2001) carried out from September 2010 to April 2011. In total, 34 line transects covering $340 \mathrm{~km}$ were walked during the survey period. The line transects varied in length from 1.8$2.5 \mathrm{~km}$ and were laid out following a stratified random design within the study area (Harihar $e t$ al., 2009). On every walk we recorded the encountered species and their group size; sighting angle measured using a hand-held compass and sighting distance measured by a laser range finder (Jathanna et al., 2003). We modelled detection functions to estimate the population density of principal prey species using program Distance 5.0 (Thomas et al., 2008). We used the distribution of these distances to estimate the proportion of animals sighted in the strip that is detected i.e., probability of detecting the animal as a function of perpendicular distance $(y)$, the detection function $\mathrm{g}(y)$, which allows us to estimate animal density and abundance. If the animals 
occur in well-defined clusters (e.g. flocks or herds) then detections refer to clusters rather than to individual animals. Conceptually, this could be considered in terms of effective strip width $(\mu)$, which is the distance, from the line for which as many objects are detected beyond $\mu$ as are missed within $\mu$ of the line. Thus density of individuals $(D i)$ can be estimated using the following formula: $D i=n / 2 \mu \mathrm{L},(\mathrm{n}=$ population numbers, $\mathrm{L}=$ length of the transect), A better way to view is that we expect to detect a proportion $P$ of the objects in the strip of length $L$ and width $2 w$, so that density $D$ is estimated by $D i=n / 2 w L P$. It is often convenient to measure the sighting by 'radial distance $\boldsymbol{r}$ ' and sighting angle $\theta$, rather than perpendicular distance $x$, for each of the $n$ objects detected. The $\boldsymbol{x}$ is calculated by a simple trigonometry formula: $x=r \cdot \sin \theta$.

To model detection functions, we examined the data for each species for signs of evasive movement and peaking at great distance from the line transect. Following this, the data was either truncated at great distances or re-classed so as to ensure a reliable fit of key functions and adjustment terms to the data. Akaike Information Criterion (AIC ${ }^{\mathrm{i}}$ ) and goodness-offit (GOF-p) tests were used to judge the fit of the model. Using the selected model, estimates of group density $(D g)$, group size $(G S)$, and individual density $(D i)$ were derived and tabulated (Buckland et al., 2001; Karanth et al., 2004).

Assessing Body Biomass: We derived the biomass (in $\mathrm{kg} / \mathrm{km}^{2}$ ) in the study area by multiplying population density (Di) of each species by its average unit weight which was estimated from published data on body weights and expressing it on a per- $\mathrm{km}^{2}$ basis (Eisenberg \& Lockhart, 1972; Johnsingh, 1983; Scheller, 1967; Tamang, 1982). However we compared the biomass of MTR with other South Asian Park. Body biomass was calculated using this formula $(\mathrm{x} \times \mathrm{y}=\mathrm{z})$. Whereas, $\boldsymbol{x}$ is density of the species; whereas, $\boldsymbol{y}$ is avg. body weight of the species and multiplied both values to arrive the body biomass (Johnsingh, 1983; Scheller, 1967).

\section{Results}

Population Density: The individual population density and mean group density were estimated for all the observed prey species. The best fit model is half normal key with cosine adjustment, was suited model for density estimation of all prey species (Fig. 1). This was selected on the basis of the lowest Akaike Information Criterion $\left(\mathrm{AIC}^{i}\right)$. The overall prey density was $\left(69.5 \pm 8.3\right.$ individuals $\left./ \mathrm{km}^{2}\right)$. Ungulate density was $19.0 \pm 5.5$ animals $/ \mathrm{km}^{2}$. Peafowl and langur together contributed $50.5 \pm 7.7$ individuals $/ \mathrm{km}^{2}$. The density of langur $\left(42.9 \pm 8.2\right.$ individuals $\left./ \mathrm{km}^{2}\right)$ was higher than sambar $\left(10.5 \pm 3.5\right.$ individuals $\left./ \mathrm{km}^{2}\right)$, peafowl $\left(7.6 \pm 0.6\right.$ individuals $\left./ \mathrm{km}^{2}\right)$, gaur $(5.8 \pm 1.7$ individuals $\left./ \mathrm{km}^{2}\right)$ and barking deer $(2.7 \pm 0.3$ individuals $/ \mathrm{km}^{2}$ ). The mean group size between the species is shown in the Figure 2. The variation in density estimates and abundance was partly related to the species encounter rate that tended to decrease from langur to red muntjak (Table 1). However, chital was not encountered anywhere except outside the survey area near Dharani. Also, wild boar, nilgai, rhesus macaque (Macaca mulatta) and livestock were encountered $\leq 5$ sightings, but due to insufficient data we could not estimate their density.

Body Biomass: We present body biomass, based on population density of the study area. The population density of each species was multiplied by average body weight each category to estimate biomass of the species. The average group size of observed prey species was differing from each other (Table 2). Gaur serves as a principal prey species with higher body biomass of $4632 \mathrm{~kg} / \mathrm{km}^{2}$ than Sambar $1407.0 \mathrm{~kg} / \mathrm{km}^{2}$ and least in the case of barking deer $57.7 \mathrm{~kg} / \mathrm{km}^{2}$. The overall prey species body biomass was about $6501.8 \mathrm{~kg} / \mathrm{km}^{2}$ as estimated from the study area.

\section{Discussion}

Comparison of Population Density: The results revealed that the density of langur was higher than sambar, peafowl, gaur and barking deer. The density estimate figures clearly indicate that MTR has healthy wild prey population. The estimated wild prey density was 69.5 individuals $/ \mathrm{km}^{2}$, which is higher than the previously reported density of about 5.2 animals $/ \mathrm{km}^{2}$ from the same study area a decade ago by Karanth et al. (2004). Though the previous and present estimates were followed same line transect by distance sampling method, the data were analysed in different ecological softwares in both studies. Notably 
the present sampling effort was higher than the previous study (Karanth, 2004). Besides this reason, after 2006, several tribal villages have voluntarily vacated from the core area of the Park, resulting in the recovery of native vegetation and wildlife contributing to undisturbed habitat. Earlier studies also document similar recoveries in tiger population (Dinerstein et al., 1999; Dinerstein, 2003; Harihar et al., 2009; Karanth \& Sunquist, 1992). It is evident that ensuring long-term conservation of the prey base requires formulating and implementing appropriate management interventions to eliminate / minimize anthropogenic disturbances. Jhala et al. (2011) estimated the Tiger density of about 3.04 individuals $/ 100 \mathrm{~km}^{2}$ from the MTR. So, the increased prey density may indeed be able to support large carnivore population of the park. These results are comparable with other sites of the Indian subcontinent (Sankar et al., 2010). Sariska Tiger Reserve harbors relatively high density of wild prey species, than Nagarhole and other south Asian sites given in the Table 3.

Table 1: Estimated wild prey species density in MTR (SE, standard error; T, total effort; AIC, akaike information criterion; $\check{D} i \pm \mathrm{SE}$, population density; $\mathrm{Dg} \pm \mathrm{SE}$, average group density; $\mathrm{n} / \mathrm{L}$, encounter rate; ESW, effective strip width; $95 \%$ CI, lower limit and upper limit).

\begin{tabular}{|c|c|c|c|c|c|c|c|}
\hline Species & $\mathbf{T}(\mathbf{k m})$ & $A_{I C}{ }^{i}$ & $\check{D} i \pm \mathrm{SE}$ & $\mathrm{Dg} \pm \mathrm{SE}$ & $\mathrm{n} / \mathbf{L}$ & ESW & $95 \% \mathrm{CI}$ \\
\hline Gaur & 340.0 & 198.9 & $5.8 \pm 1.7$ & $0.9 \pm 0.2$ & 0.11 & 60.4 & $3.2-10.5$ \\
\hline Sambar & 340.0 & 201.6 & $10.5 \pm 3.5$ & $1.4 \pm 0.3$ & 0.17 & 40.7 & $5.5-20.1$ \\
\hline B. Deer & 340.0 & 253.4 & $2.7 \pm 0.3$ & $1.2 \pm 0.2$ & 0.12 & 48.1 & $1.2-04.5$ \\
\hline Langur & 340.0 & 855.0 & $42.9 \pm 7.2$ & $6.1 \pm 1.2$ & 0.35 & 40.9 & $30.8-59.7$ \\
\hline Peafowl & 340.0 & 316.6 & $7.6 \pm 0.6$ & $1.7 \pm 0.9$ & 0.10 & 46.1 & $6.4-08.9$ \\
\hline All Prey & 340.0 & 191.5 & $69.5 \pm 13.3$ & $11.4 \pm 2.8$ & 0.85 & 59.3 & $39.5-88.9$ \\
\hline
\end{tabular}

Table 2: Biomass density of the wild prey species recorded from the MTR (RgY, range of observed group sizes; $\tilde{\mathrm{N}}$, number of group detected); Body biomass estimated using this formula: $\boldsymbol{x} \times \boldsymbol{y}=\boldsymbol{z}$.

\begin{tabular}{lccccc}
\hline \multicolumn{1}{c}{ Species } & $\mathbf{R g Y}$ & $\tilde{\mathbf{N}}$ & $\begin{array}{c}\boldsymbol{D i} \pm \boldsymbol{S E} \\
\boldsymbol{x}\end{array}$ & $\begin{array}{c}\text { Avg. body Weight } \\
(\mathbf{k g}) \boldsymbol{y}\end{array}$ & $\begin{array}{c}\text { Body Biomass } \\
(\mathbf{k g . k m})\end{array}$ \\
\hline Gaur & $1-20$ & 25 & $5.8 \pm 1.7$ & 800 & 4632 \\
Sambar & $1-7$ & 70 & $10.5 \pm 3.5$ & 212 & 1407 \\
Barking deer & $1-4$ & 29 & $2.7 \pm 0.3$ & 20 & 57.8 \\
Langur & $1-20$ & 112 & $42.9 \pm 7.2$ & 8 & 386.1 \\
Peafowl & $1-7$ & 42 & $7.6 \pm 0.6$ & 2.5 & 19.0 \\
Total & - & 176 & - & - & 6501.8 \\
\hline
\end{tabular}

Comparison of Body Biomass: The reported body biomass of gaur and sambar in MTR are comparable with other protected areas in the tropical forests (Karanth et al., 1995). However, the reported biomass density of sambar in MTR was lower than Sariska $\left(3510.8 \mathrm{kgkm}^{2}\right)$, the langur body biomass was higher in MTR $\left(386.1 \mathrm{~kg} / \mathrm{km}^{2}\right.$; Sankar et al., 2010) and details about other sites' body biomass details are given in Table 4 . The estimated gaur body biomass was lower than Nagarahole and higher than other sites compared. The attribution seems to be not relevant to gaur. MTR has a large area of continuous deciduous forest $\left(\geq 1600 \mathrm{~km}^{2}\right)$ that can support a good population of langur and other ungulate species. However, their contribution to prey could be limited as is the case of other smaller prey species (Ramesh et al., 2012). The population densities of large carnivores are directly related to biomass density of the wild prey (Karanth et al., 2004; Ramesh et al., 2009). Thus, wild prey species are indicators to the health of forest ecosystems and monitoring their populations through noninvasive technique such as distance sampling is proving to be much more cost effective and providing robust results (Lancia et al., 1994). This study provides baseline information on wild prey base density and biomass in the MTR, one of the few protected areas (PA) representing India's remnant contiguous forests.

Implications for conservation: MTR is one of the protected areas showing increasing trend of wild prey density. Tigers are mostly dependent on wild prey rather than domestic livestock for food as in many other areas of the Indian subcontinent (Jathanna et al., 2003; Karanth \& 
Nichols, 2002; Karanth et al., 2004). From the present study it can be concluded that MTR, due to its high density of wild prey base, has the potential to accommodate a viable population of tigers (Buckland et al., 2001; Harihar et al., 2009; Narasimmarajan et al., 2012). Some villages situated near the park boundaries should be relocated, because fishing and grass cutting are perceived to be most serious threat to the MTR (Narasimmarajan et al., 2012). Thus, strict protection of the habitat supplemented by regular foot patrolling and monitoring of tigers and their prey population using comparable scientific methods is essential for MTR to emerge as one of the most important areas for tiger conservation landscape in Central India.

Table 3: Comparison of wild prey species density in South Asian reserves, Sources: ESA, Nagarahole (Karanth \& Nicols, 1992); BPR, Bandipur (Johnsingh, 1983); KNH, Kanha (Schaller, 1967); WPT, Wilpattu (Eisenberg \& Lockhart, 1972); BRD, Bardia (Dinerstein, 1980); CHN, Chitwan (Tamang, 1982); KMTR, KalakadMundanthurai (Ramesh et al., 2012); and STR, Sariska (Sankar et al., 2010); NA, data not reported.

\begin{tabular}{lccccccccc}
\hline \multirow{2}{*}{ Species } & \multicolumn{8}{c}{ Densities $\left(\mathbf{a n i m a l s}_{\mathbf{1}} \mathbf{k m}^{\mathbf{2}}\right)$ at different sites of South Asia } \\
\cline { 2 - 11 } & MTR & ESA & BPR & KNH & WPT & BRD & CHN & KMTR & STR \\
\hline Gaur & 5.7 & 9.6 & 0.5 & 0.7 & NA & NA & NA & 3.6 & 0 \\
Sambar & 10.5 & 5.5 & 7.0 & 0.9 & 1.2 & 3.5 & 16.8 & 7.0 & 26.2 \\
Barking Deer & 2.7 & 4.2 & 1.0 & 0.4 & 1.7 & 6.6 & NA & NA & 0 \\
Langur & 42.9 & 23.8 & 7.5 & 46.2 & 2.8 & 9.6 & NA & 9.9 & 22.8 \\
Peafowl & 7.5 & NA & NA & NA & NA & NA & NA & 0.41 & 125.2 \\
\hline
\end{tabular}

Table 4: Comparison of biomass of wild prey and domestic herbivores at tropical sites. Sources: the same as in Table 3; 0, data not reported by source.

\begin{tabular}{|c|c|c|c|c|}
\hline \multirow{2}{*}{ Area } & \multirow{2}{*}{ Habitat type } & \multicolumn{3}{|c|}{ Biomass density $\mathrm{kg} / \mathrm{km}^{2}$} \\
\hline & & WLBD & DMBD & Total \\
\hline Melghat Tiger Reserve & Dry deciduous forest & 6501.8 & 0 & 6501.8 \\
\hline Nagarahole & Deciduous forest & 14744 & 350 & 15094 \\
\hline Bandipur & Dry forest-woodland & 14520 & 0 & 14520 \\
\hline Kanha & Moist forest-meadows & 1592 & 2925 & 4517 \\
\hline Wilpattu & Moist forest-meadows & 766 & 0 & 766 \\
\hline Bardia & Moist forest-grasses & 3101 & 0 & 3101 \\
\hline Chitwan & Moist forest-grasses & 2581 & 0 & 2581 \\
\hline Kalakad-Mundanthurai & Moist evergreen-swamps & 2648 & 0 & 2648 \\
\hline Sariska & Semi-arid forest & 10072 & 11545 & 21618 \\
\hline
\end{tabular}

\section{Acknowledgements}

We thank the Director and Dean (WII) and the Chief Wildlife Warden, Maharashtra for granting permission to work in MTR. We sincerely thank the Member Secretary NTCA, New Delhi for their constant support. We would like to thank the Field Director, Deputy Director and Range officers of MTR for their logistic support extended in the field. Special thanks to B. B. Barman, L. Puia and M. Naveen, for their help during the field work. We thank our field assistants, drivers and staff of Forest Department for their assistance during field work.

\section{Literature cited}

Anderson, D. R., J. L. Laake, B. R. Crain, and K. P. Burnham, 1979. Guidelines for the transect sampling of biological populations. Journal of Wildlife Management, 43: 70-78.
Buckland, S. T., D. R. Anderson, K. P. Burnham, J. L. Laake, D. L. Borchers, and L. Thomas, 2001. Introduction to distance sampling. Oxford University Press, London: 22.

Dinerstein, E., 1980. An ecological survey of Royal Karnali-Bardia wildlife reserve, Nepal. Biological conservation, 18: 5-38.

Dinerstein, E., 2003. The return of the unicorns: The natural history and conservation of the greater one-horned rhinoceros. Columbia Cambridge University Press: 316.

Dinerstein, E., A. Rijal, M. Bookbinder, B. Kattel, and A. Rajuria, 1999. Tigers as neighbours: efforts to promote local guardianship of the endangered species in lowland Nepal. In: Seidensticker, J., S. Christie, P. Jackson (eds.). Riding the tiger: tiger conservation in humandominated landscapes. Cambridge University Press, Cambridge: $316-333$. 
Eisenberg, J. F. and M. Lockhart, 1972. An population reconnaissance of Wilpattu National Park. Ceylon. Smithsonian Contributions Zoology, 101: 1-118.

Harihar, A., B. Pandav, and S. P. Goyal. 2009. Responses of tiger (Panthera tigris) and their prey to removal of anthropogenic influences in Rajaji National Park, India. European Journal of Wildlife Research, 55: 97-105.

Jathanna, D., K. U. Karanth, and A. J. T. Johnsingh, 2003. Estimation of large herbivore densities in the tropical forests of southern India using distance sampling. Journal of Zoology (London), 261: 285-290.

Jhala, Y. V., Q. Qureshi, and R. Gopal, 2011. Status of Tigers, Co-predators and Prey in India. National Tiger Conservation Authority, Govt. of India, New Delhi, and Wildlife Institute of India, Dehradun: 169.

Johnsingh, A. J. T., 1983. Large mammalian prey-predators in Bandipur. Journal of the Bombay Natural History Society, 80: 1-57.

Karanth, K. U. and J. D. Nichols, 2002. Monitoring Tigers and their Prey. Centre for Wildlife Studies, Bangalore, India: 235.

Karanth, K. U. and M. E. Sunquist, 1992. Population structure, density and biomass of large herbivores in the tropical forests of Nagarahole, India. Journal of Tropical Ecology, 8: 21-35.

Karanth, K. U., J. D. Nichols, N. Kumar W. A. Link, and J. E. Hines, 2004. Tigers and their prey: predicting carnivore densities from prey abundance. Proceedings of the National Academy of Sciences of the United States of America, 101: 4854-4858.

Karanth, U. K. and M. E. Sunquist, 1995. Prey selection by tiger, leopard and dhole in tropical forests. Journal of Animal Ecology, 64: 439-450.

Kumara, H. N., S. Rathnakumar, M. A. Kumar and M. Singh 2012. Estimating Asian elephant (Elephas maximus) density through distance sampling in the tropical forests of Biligiri Rangaswamy Temple Tiger Reserve, India. Tropical Conservation Science, 5: 163-172.

Lancia, R. A., J. D. Nichols and K. N. Pollock, 1994. Estimation of number of animals in wildlife populations. In: T. A. Bookhout (ed.). Research and Management Techniques for Wildlife and Habitats. Bethesda. The Wildlife Society, Maryland: 215-253.

Mahabal, A., 2005. An overview Fauna of Melghat Tiger Reserve, Conservation Area Series, 24. Zoological Survey of India, Kolkata: $1-10$.

Narasimmarajan, K., B. B. Barman, and L. Puia, 2012. Population density and group size of the Grey Junglefowl (Gallus sonneratii) in the Melghat Tiger Reserve, Maharashtra, Central India. Journal of Threatened Taxa, 4: 2723-2726.

Ramesh, T., V. Snehalatha, K. Sankar, and Q. Qureshi, 2009. Food habits and prey selection of tiger and leopard in Mudumalai Tiger Reserve, Tamil Nadu, India. Journal of Scientific Transactions of Environment and Technovation, 2: $170-181$.

Ramesh, T., N. Sridaran K. Sankar Q. Qureshi M. K. Selvan N. Gokulakannan P. Francis, K. Narasimmarajan, Y. V. Jhala, and R. Gopal, 2012. Status of large carnivores and their prey in tropical rainforest of South Western Ghats, India. Tropical Ecology, 53: 137-148.

Sankar, K., Q. Qureshi, P. Nigam, P. K. Malik, P. R. Sinha, R. N. Mehrotra, R. Gopal, S. Bhattacharjee, K. Mondal, and S. Gupta, 2010. Monitoring of reintroduced tigers in Sariska Tiger Reserve, Western India: preliminary findings on home range, prey selection and food habits. Tropical Conservation Science, 3: 301-318.

Schaller, G. B., 1967. The deer and the Tiger. A study of Wildlife in India. University of Chicago Press, Chicago, IL: 370.

Tamang, K. M., 1982. The status of the tiger (Panthera tigris) and its impact on principal prey populations in the Roula Chitwan National Park, Nepal. Ph.D Dissertation, Michigan state University, East Lansing: 184.

Thomas, L., J. L. Laake, S. Strindberg, F. F. C. Marques, S. T. Buckland, D. L. Borchers, D. R. Anderson, K. P. Burham, S. L. Hedley, J. R. Pollard, and J. R. B. Bishop, 2008. Distance 5.0 Release 2. Research unit for wildlife population assessment, University of St. Andrews, UK $\langle$ http://www.ruwpa.st-and.ac.uk/distance/>. 


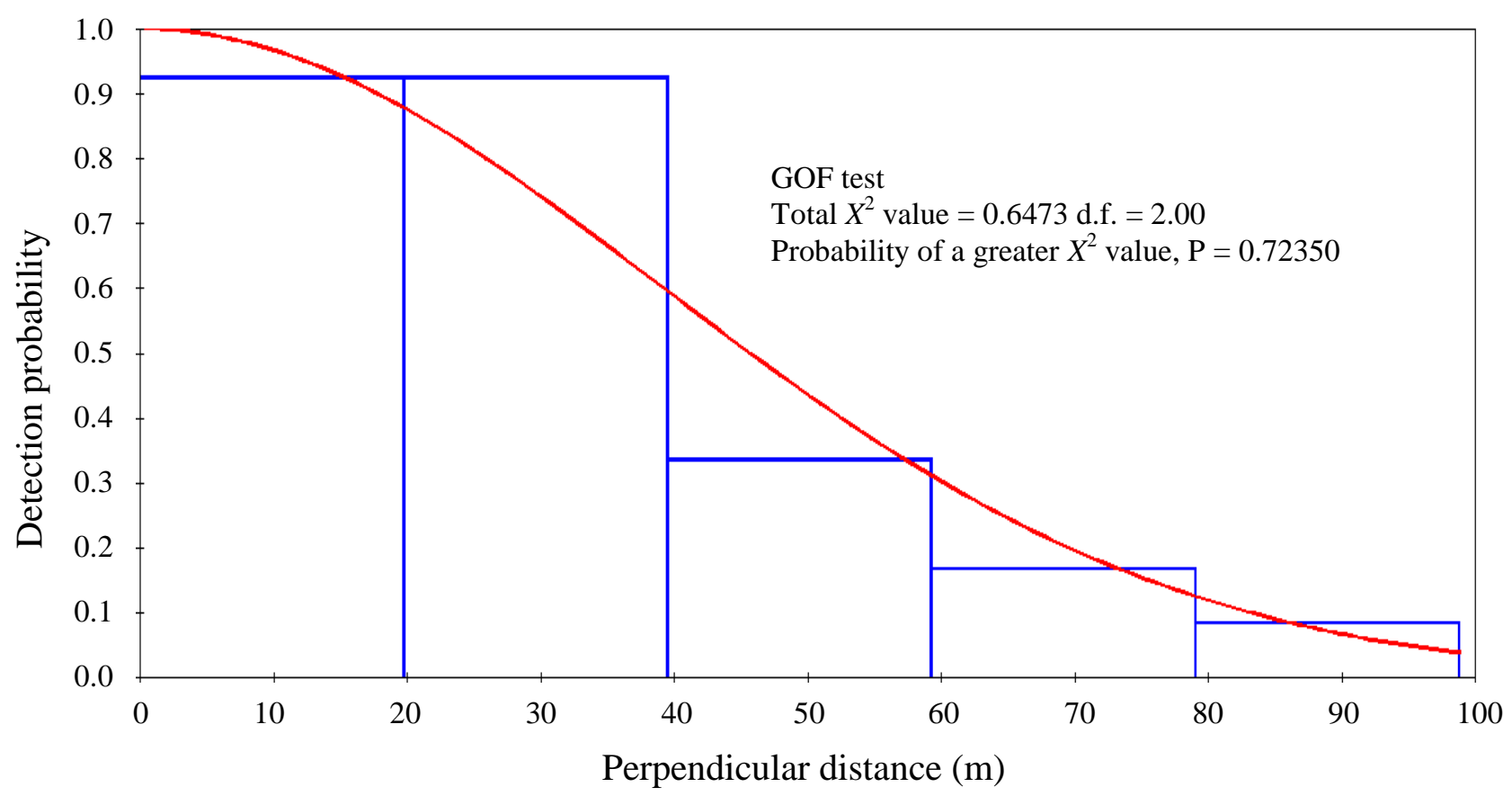

Figure 1: Results of model fitted in the DISTANCE to estimate detection probability and effective strip width of all prey species sightings in the dry deciduous habitats of MTR.

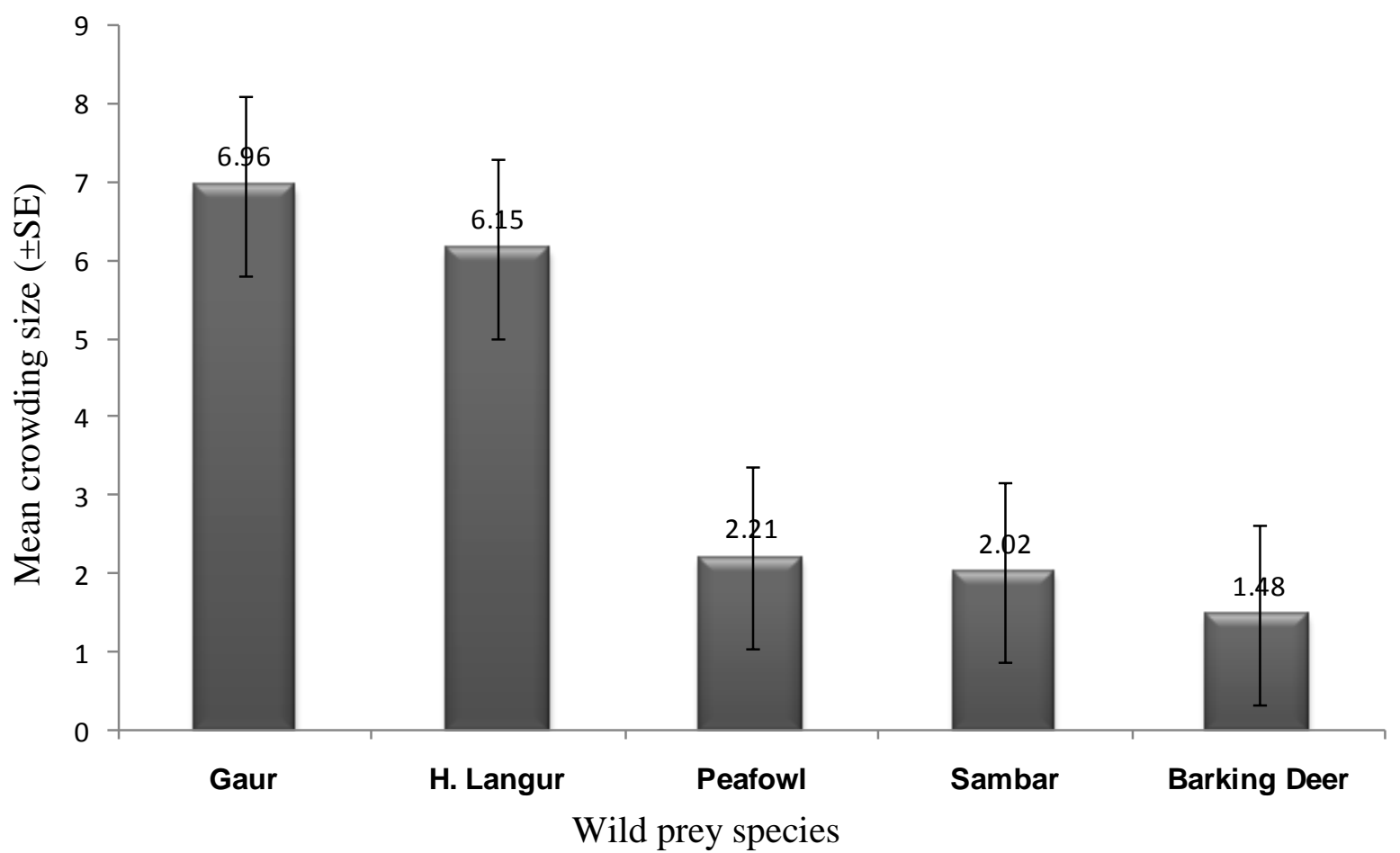

Figure 2: Mean crowding size of the observed wild prey species in the MTR between from September 2010 to April 2011. 